Reprod. Nutr. Dévelop., 1985, 25 (1 A), 127-139.

\title{
Attachement des Ciliés du caecum de Cheval aux fragments végétaux. - Dégradation des chloroplastes. - Attachement des bactéries aux Ciliés du caecum.
}

\author{
Annie BONHOMME-FLORENTIN ( ${ }^{1}$ )
}

LA 040138, CNRS Clermont-Ferrand et Zoologie, UER Sciences, Reims.

Summary. Attachment of horse cecum ciliates to plant tissues, chloroplast degradation, and attachment of bacteria to the cecum.

Cecum microfauna association with different plant tissues was examined by scanning and transmission electron microscopy. The ciliates were attached to the damaged areas of the leaves and their highest concentrations were found on the epidermis and mesophyll tissues. The degradation of plant tissue was due to protozoal ingestion of the plant fragments. The morphology of ingested envacuolized chloroplasts changed rapidly, showing different stages of digestion inside the ciliate endoplasm. Intact chloroplasts were rarely observed but the grana of fragmented thylakoid membranes was often seen. The chloroplasts then appeared in concentric rings resembling pseudomyelinic figures. Plastoglobuli indicated the chloroplastic origin of these figures.

Cecum microflora association with the microfauna showed that the different morphological types of cecal bacteria had three ways of attaching : some appeared to be attached via small amounts of extracellular material and some by capsule - like material ; others (bacilli), due to an electron-dense outer layer, were observed to adhere so closely that they conformed to the shape of the ciliate.

\section{Introduction.}

La digestion de la cellulose et du matériel fibeux végétal, essentielle dans la nutrition des herbivores, dépend de la capacité des microorganismes endosymbiotes à dégrader les parois des cellules végétales et à fermenter les hydrates de carbone. La digestibilité des fourrages varie en fonction de leur composition, de leur structure; l'épiderme cutinisé et les tissus lignifiés résistent à l'activité microbienne. La digestion des polysaccharides insolubles des cellules de la paroi végétale semble nécessiter l'attachement préalable des microorganismes. Cet attache-

(1) Adresse postale : Zoologie, UER Sciences, B.P. 347, 51062 Reims Cedex, France. 
ment dépend des conditions physicochimiques prévalant dans l'environnement du côlon et du caecum chez le Cheval, du rumen chez le Ruminant, aussi bien que de la nature du substrat végétal.

De même que les Protozoaires du rumen, les Protozoaires du caecum colonisent les débris végétaux. En culture in vitro, les Ciliés sont toujours associés aux fragments végétaux ; in vivo, ils sont séquestrés dans le tapis végétal nécessaire à leur maintien, dans le caecum comme dans le rumen. Le taux de passage des Protozoaires du rumen dans l'omasum ne suit pas celui du flux liquide. II est seulement de l'ordre de 20 à $40 \%$ selon Jouany et Senaud (1978) et Coleman et al., (1980).

De même que les protozoaires du rumen, les Ciliés du côlon et du caecum ingèrent et digèrent les particules alimentaires telles que l'amidon, ainsi que les bactéries (Bonhomme, 1969, 1971, 1974).

Le but de cette étude est de montrer les relations morphologiques existant entre la microfaune du caecum de cheval et son environnement végétal et bactérien.

\section{Matériel et méthodes.}

1) Source des protozoaires. - Le contenu de caecum de Cheval fraîchement abattu est filtré sur deux épaisseurs de gaze et placé au bain-marie à $39^{\circ} \mathrm{C}$. La fermentation déplace les débris végétaux que l'on élimine. Le filtrat comporte essentiellement les genres Cycloposthium et Didesmis.

\section{2) Préparation des substrats.}

A) Trois substrats végétaux sont utilisés : feuilles de trèfle (Trifolium repens), feuilles de chiendent (Agropirum repens), tiges de trèfle.

Les feuilles fraîches sont coupées transversalement et les tiges fraîches sont coupées longitudinalement et transversalement en fragments de $8 \mathrm{~mm}$ de longueur environ pour être plus accessibles aux microorganismes.

B) Préparation des chloroplastes. - Les chloroplastes sont préparés à partir de feuilles fraîches de trèfle Trifolium repens; $10 \mathrm{~g}$ de feuilles sont broyées au mixer dans $50 \mathrm{ml}$ de tampon saccharose (Hall et al., 1974) pendant $5 \mathrm{~min}$. Le broyat est ensuite filtré sur quatre épaisseurs de gaze. Le filtrat est centrifugé à $4200 \mathrm{~g}$ pendant $5 \mathrm{~min}$. Les chloroplastes, non utilisés pour l'incubation avec les Protozoaires, sont remis en suspension dans le tampon saccharose. Une partie du culot des chloroplastes est utilisée pour être fixée au glutaraldéhyde $12 \%$ dans le tampon saccharose) pendant $2 \mathrm{~h}$ à $4^{\circ} \mathrm{C}$.

\section{3) Conditions d'incubation.}

A) $2 \mathrm{ml}$ de filtrat de Ciliés sont mis à incuber avec les fragments de végétaux à $39^{\circ} \mathrm{C}$ sous atmosphère d'aozte dans $10 \mathrm{ml}$ de solution minérale de Hungate (débarrassée de son oxygène par un barbotage gazeux d'azote), pendant $3 \mathrm{~h}$ à $18 \mathrm{~h}$. 
B) 0,4 $\mathrm{ml}$ de chloroplastes frais ou fixés, lavés à l'eau distillée sont mis en incubation avec $3 \mathrm{ml}$ de filtrat de Ciliés dans $7 \mathrm{ml}$ de solution minérale de Hungate à $39^{\circ} \mathrm{C}$, sous atmosphère d'azote, pendant $15 \mathrm{~min}, 3 \mathrm{~h}$ et $5 \mathrm{~h}$.

4) Préparation des Ciliés et des fragments végétaux pour l'étude de l'attachement en microscopie électronique à balayage (MEB). - Après le temps d'incubation, les cultures sont centrifugées $3 \mathrm{~min}$ à $300 \mathrm{~g}$. Pour $\mathrm{A}$ :

a) Le culot est alors fixé par un mélange : acide osmique $2 \%$ (6 volumes) ; solution saturée de chlorure mercurique (1 volume) pendant $20 \mathrm{~min}$.

b) Le culot fixé est lavé une fois à l'eau distillée, puis subit la déshydratation en passant dans la série des alcools $50^{\circ}, 70^{\circ}, 80^{\circ}, 90^{\circ}, 95^{\circ}$ et $100^{\circ}$ (bains de $20 \mathrm{~min}$ ). Entre chaque opér3... nn, le culot (Protozoaires-Bactéries-fragments végétaux) est centrifugé à $300 \mathrm{~g}$ pendant $3 \mathrm{~min}$.

c) L'échantillon est placé dans un mélange alcool 100-acétate d'isoamyle (vol/vol) pendant $20 \mathrm{~min}$, puis dans l'acétate d'isoamyle pendant une à deux heures.

d) II est ensuite séché par la technique de séchage au point critique (Anderson, 1951), en utilisant le gaz carbonique liquide.

e) L'échantillon sec est alors déposé collé (par du papier collant transparent double face ou par une colle à l'argent) sur un disque d'aluminium placé dans un évaporateur pour être métallisé ( $6 \mathrm{~min}$ ) par un alliage or-palladium, selon la technique du sputtering (Guillaumin (1980)). $15 \mathrm{kV}$.

f) II est observé ensuite au microscope électronique à balayage JSM 25 S à

5) Préparation des Ciliés pour l'étude de la dégradation des chloroplastes en microscopie électronique à transmission (MET). - Après le temps d'incubation, les cultures sont centrifugées $3 \mathrm{~min}$ à $300 \mathrm{~g}$.

a) Le culot subit alors une double fixation au glutaldéhyde $4 \%$ dans le tampon cacodylate $(0,05 \mathrm{M} \mathrm{pH} \mathrm{7,5)}$ pendant $3 \mathrm{~h}$ et à l'acide osmique $2 \%$ dans le tampon acétate-véronal ( $/ \mathrm{v}$ ) (d'après Palade 1952) pendant $1 \mathrm{~h}$. Une partie des Ciliés ne subit qu'une seule fixation à l'acide osmique.

b) Le culot fixé est lavé dans le tampon acétate-véronal, subit la déshydratation dans la série des alcools $50^{\circ}, 70^{\circ}, 80^{\circ}, 95^{\circ}$ et $100^{\circ}$ (bains de $1 \mathrm{~h}$ ) et 1 bain $d^{\prime}$ une nuit dans l'alcool $100^{\circ}$, puis passe dans plusieurs bains d'oxyde de propylène et $d^{\prime}$ 'alcool puis d'oxyde de propylène pur.

c) Le culot est inclus dans l'araldite.

d) Les échantillons sont ensuite coupés à I'ultramicrotome Reichert OMU II. Les coupes ultra-fines sont contrastées par la double coloration à l'acétate d'uranyle en solution alcoolique et au citrate de plomb selon Reynolds (1963). Elles sont examinées au microscope électronique JEM $100 \mathrm{C}$ à une tension de $80 \mathrm{kV}$.

6) Préparation des Ciliés et des Bactéries pour l'étude de l'attachement des Bactéries aux Ciliés en microscopie électronique à transmission (MET). - Le filtrat de contenu de caecum est centrifugé $5 \mathrm{~min}$ à $300 \mathrm{~g}$. Le culot comportant protozoai- 
res et bactéries est lavé à l'eau distillée, fixé au glutaraldéhyde puis à l'acide osmique, lavé dans le tampon acétate-véronal, et inclus dans l'araldite ainsi qu'il l'a été décrit ci-dessus (5). Les coupes ultrafines sont également contrastées selon la technique de Reynolds (1963).

\section{Résultats.}

1) Etude des relations des Ciliés et des fragments végétaux. Attachement au substrat végétal. Ingestion et dégradation des chloroplastes.

L'étude des fragments végétaux provenant du résidu de filtration de contenu de caecum montre essentiellement la présence de deux genres de Ciliés du caecum Cycloposthium et Didesmis, dans les cavités creusées dans ces fragments (fig. 1c, d).

Une observation des Ciliés in toto provenant du filtrat frais du contenu de caecum montre que les grandes espèces ingèrent essentiellement des débris végétaux. De grands fragments s'étendent du cytopharynx au cytopyge traversant le sac endoplasmique et parfois même, le Cilié de part en part (fig. 2a).

Etude en MEB. L'observation au MEB de l'association de la microfaune avec différents types de fragment végétal indique que les Ciliés du caecum se sont logés dans des cavités qu'ils auraient formées dans l'épiderme inférieur des feuilles de trèfle (fig. 1a, Cycloposthium; fig. 1b, Didesmis). Sur les fragments de paille provenant directement du résidu du filtrat de contenu de caecum, on observe la présence de Didesmis et de Cycloposthium dans les cavités creusées dans les fibres sclérifiées (fig. 1c, d). Enfin, ces Ciliés se situent dans les replis de l'épiderme des feuilles de chiendent (fig. $2 b, c$ ). On les retrouve également attachés aux cellules du parenchyme de la tige de trèfle.

Etude en MET. - Avant d'être ajoutés au milieu d'incubation, les chloroplastes isolés dans un tampon de saccharose $(0,4 \mathrm{M})$ sont centrifugés et resuspendus dans la solution saline de Hungate, sans saccharose afin de maintenir l'activité des protozoaires. Dans ces conditions, se trouvant dans un milieu fortement hypotonique, la plupart des chloroplastes perdent leurs membranes externes et, pour certains, même une partie des protéines du stroma (fig. 3a). Mais ces chloroplastes ne sont pas fragmentés, et gardent une taille comparable à celle des chloroplastes intacts. Si l'enveloppe externe est à peine décelable parce que fragmentée, on remarque, par contre, l'intégrité des thylacoïdes, saccules aplatis organisés en faisceaux ou granas. On note aussi, dans le stoma plastidial, la présence de plastoglobules (globules lipidiques osmiophiles) et, parfois, des grains d'amidon. Les chloroplastes fixés au glutaraldéhyde conservent leur enveloppe externe.

Rapidement ingérés et envacuolés (fig. $3 \mathrm{~b}, \mathrm{c}$ ) dans des vacuoles individuelles, les chloroplastes perdent leur apparence morphologique caractéristique assez rapidement. On observe rarement des chloroplastes entiers envacuolés mais plutôt des faisceaux de thylacoïdes plus ou moins fragmentés avec parfois des plastoglobules. 

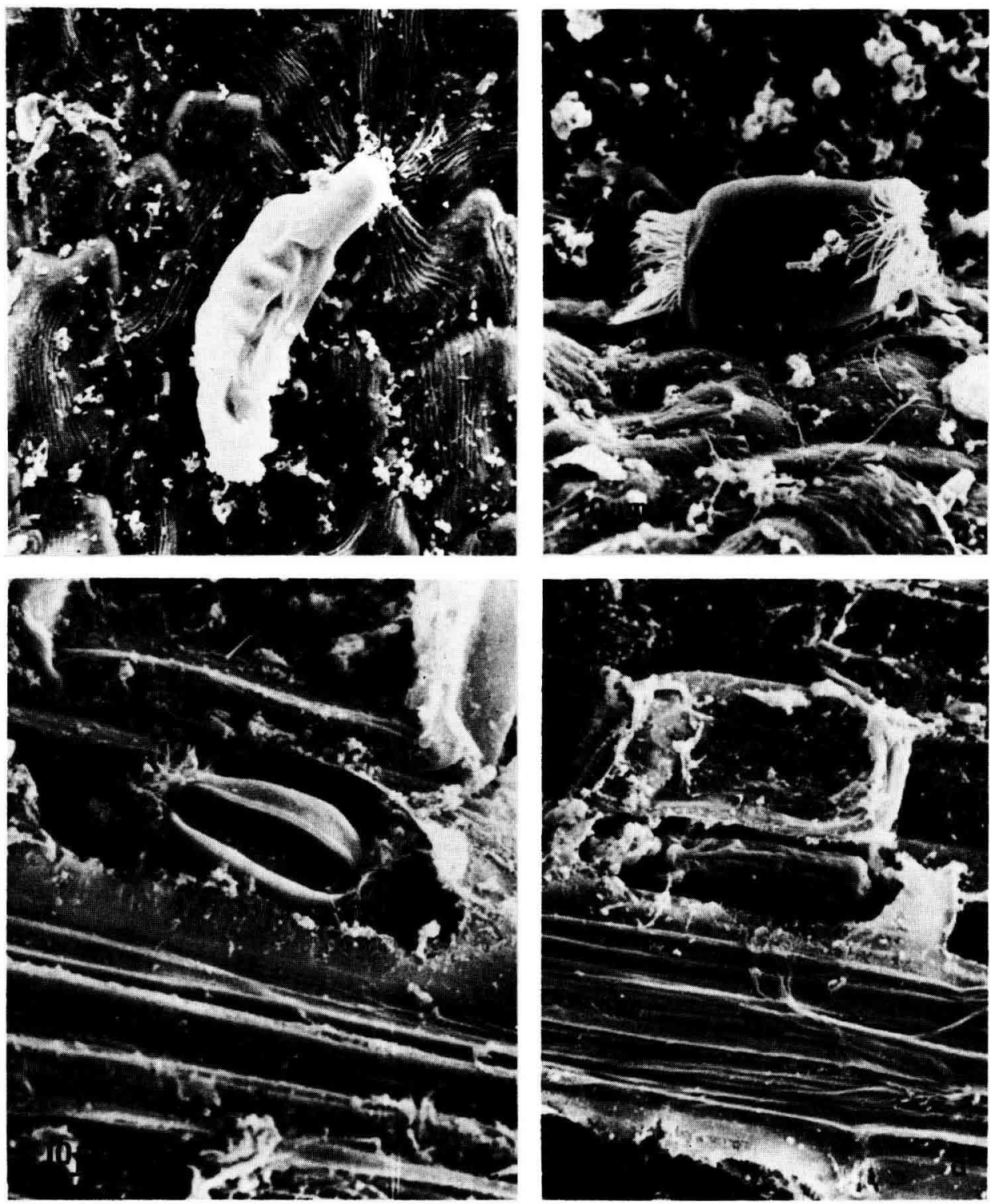

FIG. 1a, b. - Attachement des Ciliés Cycloposthium et Didesmis à l'épiderme inférieur de feuilles de trèfle.

c, d. -- Didesmis et Cycloposthium localisés dans les cavités creusées dans les fibres schlérifiées de fragments de paille directement prélevés du contenu de caecum.

Une importante variation de l'apparence des chloroplastes marque les étapes de leur digestion dans l'endoplasme des Ciliés :

Une structure très partiellement organisée avec des faisceaux de thylacoïdes encore distincts et fragmentés, envacuolés ou parfois non, reste d'abord décela- 


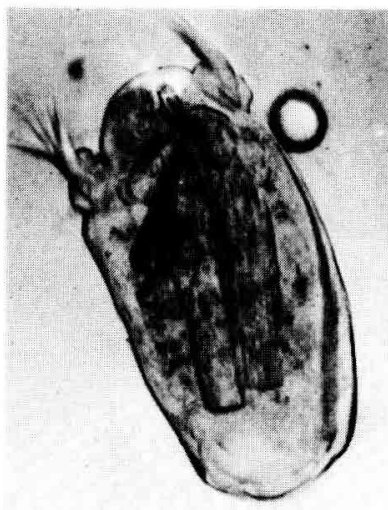

$\underline{10} \mu \mathrm{m}$
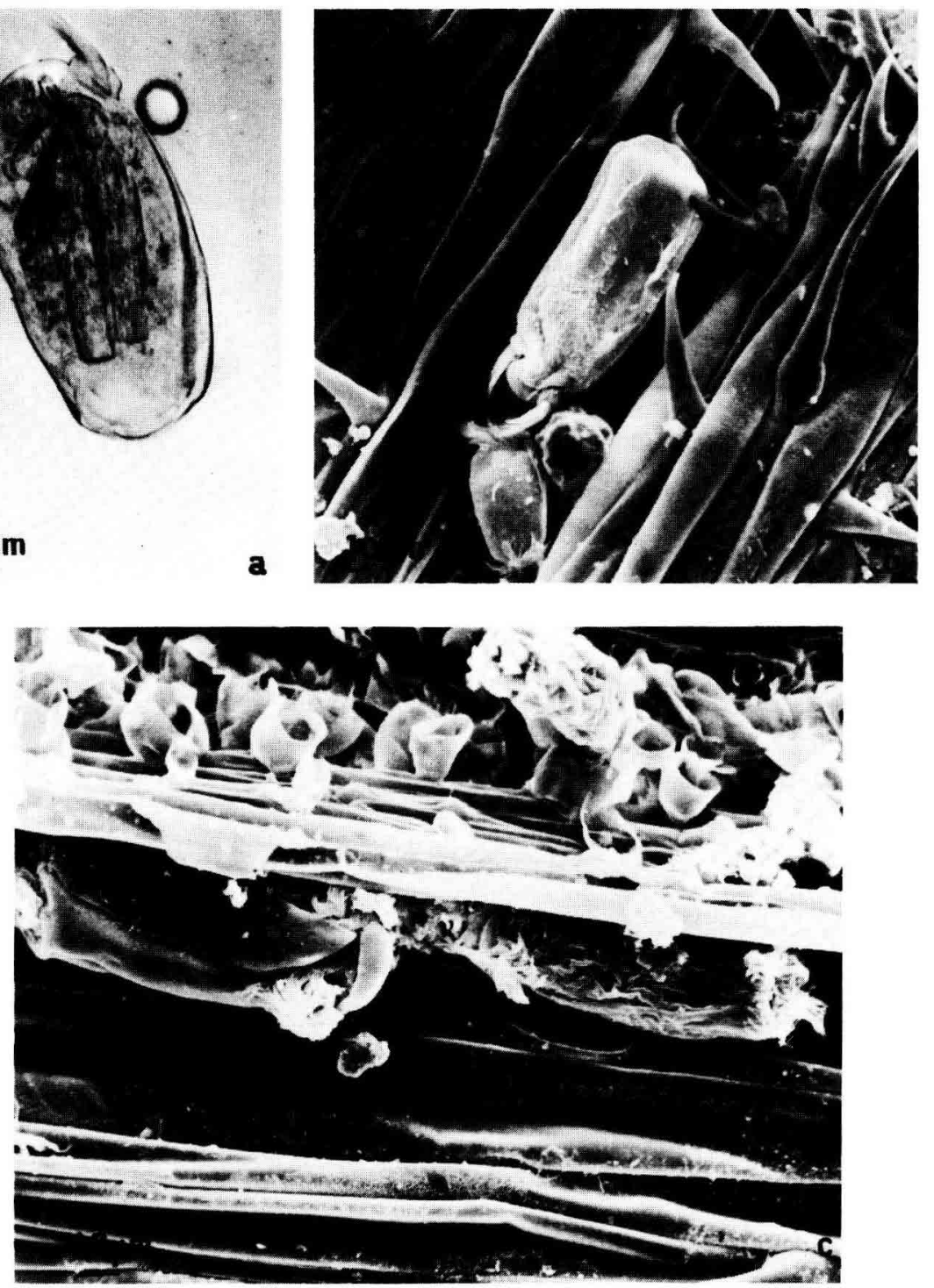

FIG. 2a. - Débris végétaux dans l'endoplasme d'un Cycloposthium.

b, c. - Ciliés Cycloposthium et Didesmis localisés dans les replis de l'épiderme de feuilles de chiendent.

FIG. 3a. - Chloroplaste de trèfle après isolement dans un tampon saccharose.

$\mathrm{T}$ : Thylacoïdes - P : Plastoglobules.

b. - Chloroplastes ingérés et envacuolés dans l'endoplasme d'un Cilié.

c. - Chloroplaste envacuolé et fragmenté, mais faisceaux de thylacoïdes distincts. 

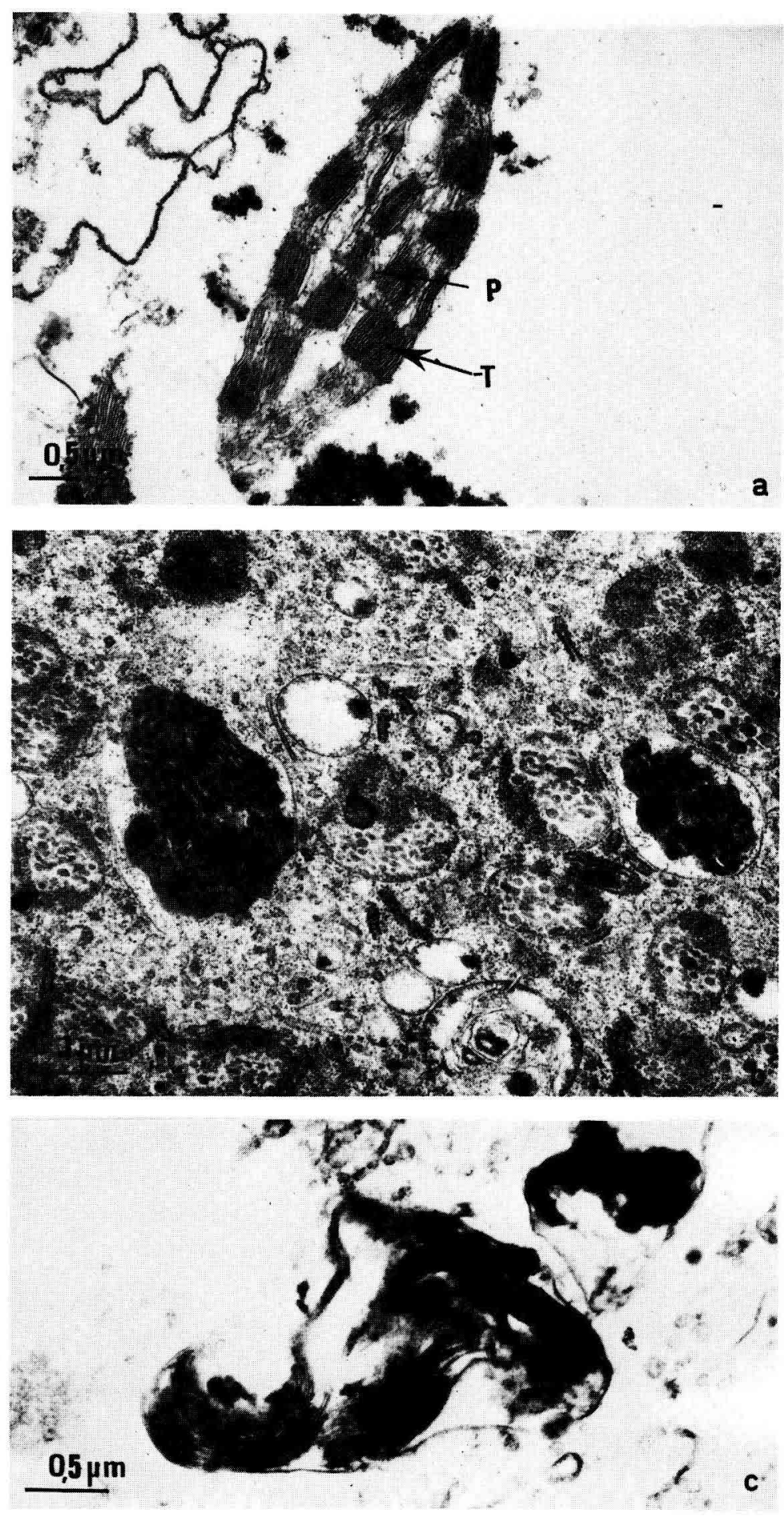
ble (fig. 3b). Puis les chloroplastes apparaissent en anneaux concentriques de matériel membranaire dans une vacuole, des plastoglobules pouvant être présents entre les membranes ; les granas ont disparu, les membranes thylacoïdes se sont réorganisées. Le matériel membranaire réorganisé ressemble à des figures myéliniques, contenues ou non dans des vacuoles (fig. 4a). L'évidence de l'origine chloroplastique des membranes est la présence de plastoglobules parmi elles.
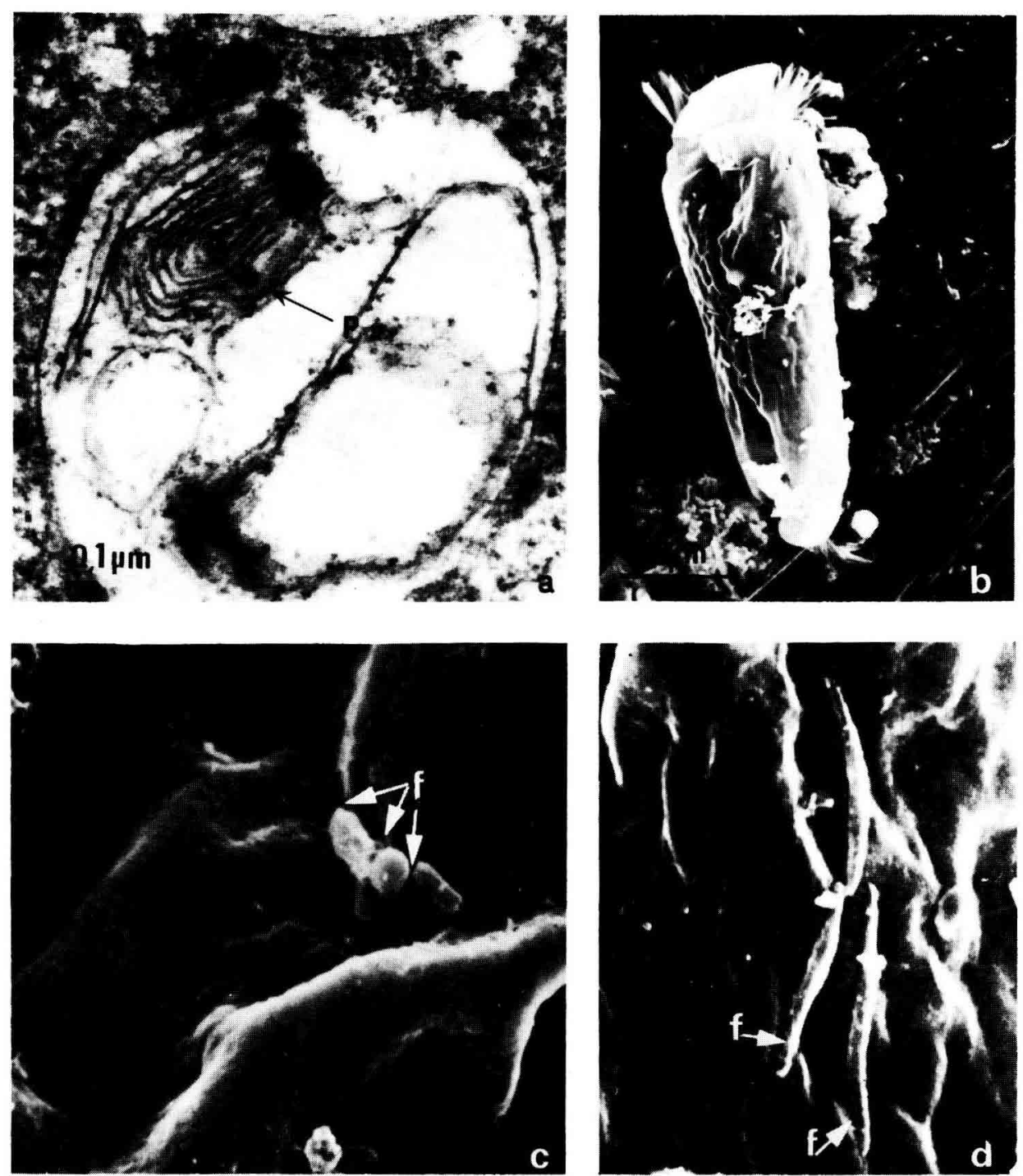

FIG. 4a. - Chloroplaste envacuolé. Matériel membranaire réorganisé donnant l'aspect d'une figure myélinique, la présence de plastoglobules $(P)$ identifie l'origine de cette figure. b, c, d. - Attachement des bactéries entre elles et à la cuticule de Cycloposthium par l'émission de substance filamenteuse extracellulaire (f). 
Au temps $5 \mathrm{~h}$ d'incubation, en présence d'une concentration élevée de chloroplastes, les Ciliés perdent déjà de leur activité mais des figures myéliniques sont observables dans leur endoplasme. Quant aux chloroplastes fixés au glutaraldéhyde à $2 \%$ à $4{ }^{\circ} \mathrm{C}$ pendant $2 \mathrm{~h}$ puis lavés avant d'être incubés avec les Protozoaires, leur incorporation par les Ciliés est moins évidente.

II est très rare d'observer des chloroplastes fixés envacuolés. On retrouve essentiellement des figures myéliniques mais leur origine est difficile à interpréter car on $\mathrm{y}$ observe peu de plastoglobules.

2) Etude des relations des Ciliés et des Bactéries. Attachement des Bactéries aux Ciliés du caecum.

Etude en MEB. - Les bactéries semblent être attachées à la surface des Ciliés par l'émission de filaments, structures fibreuses de matériel extracellulaire (fig. 4b, c, d).

Etude en MET. - Fréquemment on observe la présence de bactéries épiphytes des Ciliés Cycloposthium. Trois formes d'attachement sont observées :

a) attachement par du matériel extracellulaire, projection de mucilage, ainsi qu'Imai et Ogimoto (1978) l'ont décrit pour les bactéries attachées à la surface des Ciliés du rumen (fig. $5 \mathrm{a}, \mathrm{b}$ ).

b) attachement de type capsulaire selon Akin (1976). Ce sont essentiellement des coccis (fig. 5a).

c) attachement ou plutôt accolement. Des bactéries essentiellement des bacilles entrent en contact et épousent parfaitement la surface de la cuticule du Cilié (fig. $5 \mathrm{c}, \mathrm{d}$ ).

\section{Discussion et conclusion.}

1) Attachement des Ciliés aux fragments végétaux - Ingestion des chloroplastes. Ainsi que dans le rumen (Bauchop et Clarke, 1976 ; Bauchop, 1979 ; Imai et Ogimoto, 1978 ; Amos et Akin, 1978 ; Senaud et Grain, 1984), on observe dans le caecum une association étroite des protozoaires avec les particules végétales. Cette association s'explique par les habitudes nutritives des Ciliés qui participent à la dégradation physique des tissus végétaux et les exposent à la colonisation bactérienne et à la digestion. Bauchop (1979) et Orpin (1979) suggèrent que l'attachement aux tissus végétaux est une réponse chimiotactique aux composés solubles provenant des tissus endommagés. Comme dans le rumen, les protozoaires du caecum se situent dans les aires endommagées des tissus végétaux. Ainsi, dans nos expériences, après $3 \mathrm{~h}$ d'incubation, les fragments végétaux sont envahis de Ciliés. Didesmis et surtout Cycloposthium se localisent dans les zones dégradées du matériel végétal : épiderme et tissu mésophylle. La disposition des cellules du mésophylle ainsi que la disponibilité des nutriments qu'il contient peuvent influencer la capacité des protozoaires à envahir ce tissu. La nature microfibrillaire des parois cellulaires partiellement dégradées peut être due au déplacement des polysaccharides de la matrice (hemicelluloses et glucanes). Cycloposthium comme Epidinium pourrait-il hydrolyser partiellement les parois cellulaires des tissus végé- 

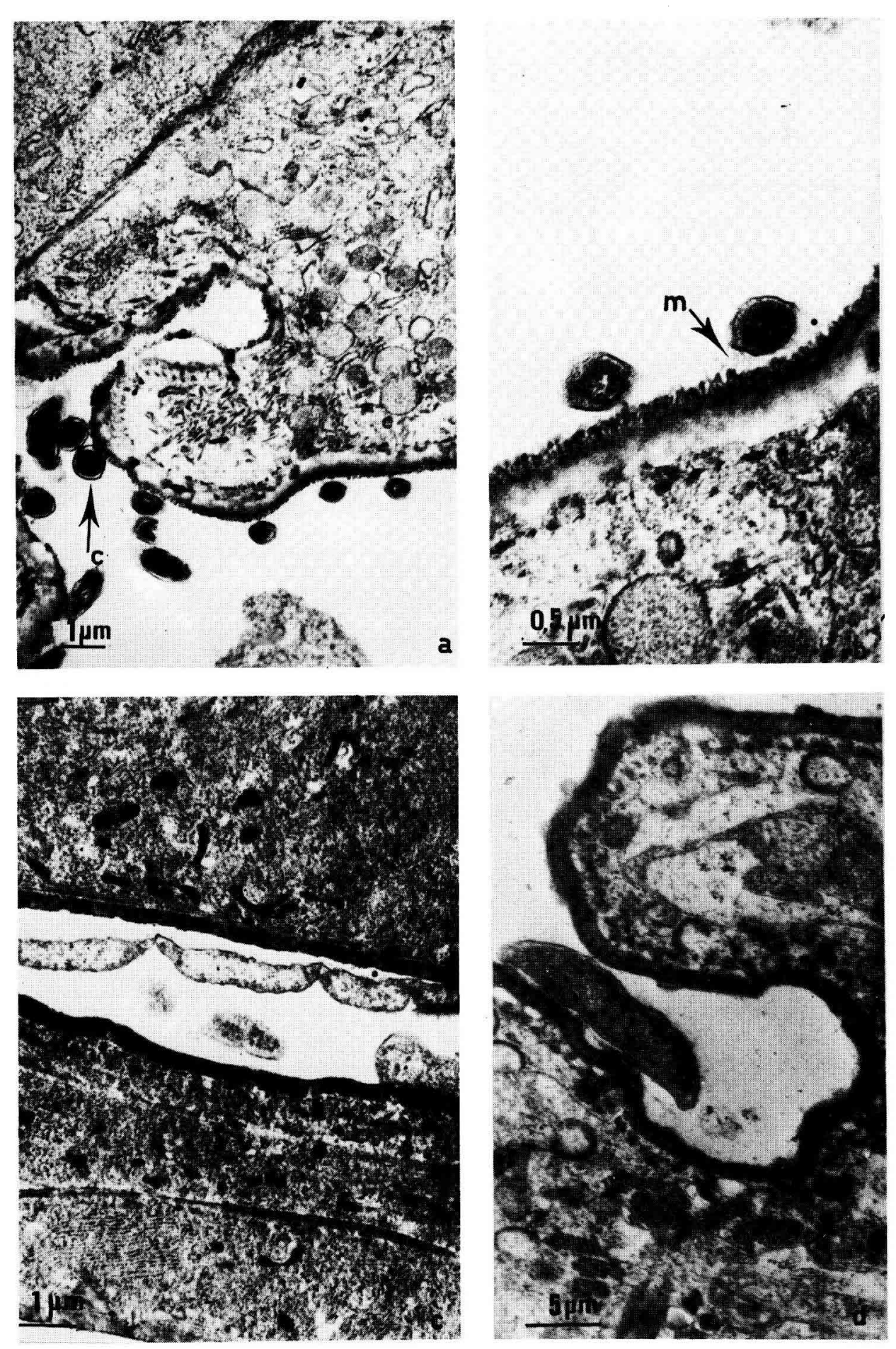
taux par des enzymes extracellulaires ? II apparaît que l'attachement est suivi de l'ingestion des fragments de tissu végétal. Cette ingestion est aidée par les cils. Cycloposthium comme Epidinium ingère des débris végétaux et des chloroplastes.

Des chloroplastes sans paroi sont présents dans l'endoplasme des Ciliés Cycloposthium. Le milieu d'incubation fortement hypotonique détruit la membrane des chloroplastes. II n'est pas possible d'incorporer du saccharose dans le milieu pour préserver la structure des chloroplastes sans inactiver les protozoaires. Aussi, l'intégrité structurale des chloroplastes est-elle sacrifiée pour conserver l'activité métabolique des Ciliés et permettre l'ingestion des particules. Les chloroplastes fixés au glutaraldéhyde pour préserver les protéines du stroma (West et Mangan, 1970) sont peu incorporés par les Ciliés. West et Mangan (1972) dans une étude de l'ingestion des chloroplastes par les Ciliés du rumen, ont noté que 50 à $60 \%$ de chloroplastes frais sont ingérés contre $22 \%$ seulement de chloroplastes fixés au glutaraldéhyde $(100 \mathrm{mM})$.

L'ingestion des chloroplastes est rapide et les faisceaux de thylacoïdes sont fragmentés en $30 \mathrm{~min}$. La structure membranaire des chloroplastes disparaît rapidement et se réorganise en anneaux ou feuillets de membranes sans grana, puis des figures pseudomyéliniques apparaissent. Ces figures ne sont pas des artéfacts dûs à la préfixation au glutaraldéhyde dans le cas d'une double fixation, car on les retrouve sur les préparations fixées à l'acide osmique seul. Les figures myéliniques se développent habituellement soit au contact de structures membranaires normales, soit dans des zones riches en lipides (Curgy, 1968). Dans ce cas, I'apparition de ce système multimembranaire semble dériver entièrement de la dégradation des chloroplastes et ne semble pas être un signe de dégénérescence localisée de la cellule puisque des plastoglobules caractéristiques des chloroplastes sont souvent présents (Lichtenhaler et Sprey, 1966).

Enfin, d'autres systèmes multimembranaires provenant de la dégradation de microorganismes ingérés, en particulier de bactéries et de petits protozoaires, ont été également observés : ils apparaissent entièrement formés à partir de ces microorganismes ingérés.

Les Ciliés du caecum de cheval, comme les Ciliés du rumen ingèrent des chloroplastes et modifient leur structure après leur envacuolisation. La démonstration de l'ingestion des fibres végétales et des chloroplastes conduit à l'hypothèse d'une dégradation enzymatique. De récents essais (Bonhomme-Florentin, 1983) ont montré l'utilisation des glucosylglycérides des chloroplastes suivie de la biohydrogénation de leurs acides gras insaturés par les Ciliés du caecum. En outre, l'ingestion de matériel cellulosique conduit à l'hypothèse d'une dégradation possible de la cellulose. Cycloposthium comme Epidinium (Bauchop, 1979) pourrait uti-

FIG. 5a, b. - Attachement de bactéries à la cuticule d'un Cilié Cycloposthium : - par une structure de type capsulaire (c), - par émission de mucilage $(\mathrm{m})$.

c. - Chaîne de bactéries dont l'une est accolée à la cuticule du Cilié ainsi qu'une bactérie lui faisant face.

d. - Bacille avec une paroi externe irrégulière, par endroit accolée à la cuticule du Cilié sans matériel fibreux extracellulaire apparent. On observe la double membrane caractéristique des bactéries gram -. 
liser principalement les composés solubles dans les tissus ingérés et les fractions non ingérées seraient rejetées. Des essais in vitro ont montré (BonhommeFlorentin, 1971, 1974) que "Cycloposthium " peut dégrader les dérivés solubles de la cellulose et a une légère activité cellulolytique sur la cellulose native.

\section{2) Attachement des bactéries aux Ciliés du caecum.}

L'attachement des bactéries aux Ciliés du caecum se fait : soit par l'intermédiaire d'une matrice fibreuse extracellulaire dense, soit par un attachement de type capsulaire, soit par une association si étroite, tel un accolement, que les points de jonction sont indistincts. Différents types de bactéries adhèrent aux Protozoaires du caecum, coccis seules ou par paires ou enchaînées (plus rarement), bâtonnets. Les bactéries (coccis essentiellement) adhèrent aux protozoaires au moyen de leurs fibres exopolysaccharidiques du glycocalyx. En ce qui concerne les bacilles qui n'émettent pas de structures fibreuses extracellulaires, ils ont une morphologie distincte par leur paroi externe irrégulière et dense aux électrons. La forme de ces bactéries s'adapte étroitement à celle du Cilié auquel elles s'attachent. La paroi de ces bacilles est comparable à la couche de polysaccharide acide des bactéries marines s'attachant à des substrats solides. Des observations similaires ont été faites sur la morphologie de bactéries d'autres habitats (marins, eau douce, terrestres, tissus infectés). Dans tous ces environnements, les structures externes servent de moyen d'attachement des cellules à leur support permettant un contact étroit avant la dégradation par leurs enzymes.

Les relations protozoaires-bactéries du caecum semblent pouvoir être mises en parallèle avec celles des protozoaires et des bactéries du rumen. Imai et Ogimoto (1978) observent également l'attachement des bactéries à la surface des ciliés soit par des projections de mucilage, soit par un attachement de type capsulaire. Mais contrairement aux bactéries du rumen, il $n^{\prime} y$ a pas de site préférentiel d'attachement à la surface des Ciliés (Cycloposthium ou Didesmis).

La signification de cet attachement n'est pas encore précisée : (1) s'agit-il d'un moyen pour échapper à la prédation par les Ciliés ? (2) s'agit-il d'un autre moyen de subsistance?

Selon Imai et Tsunoda (1972), les bactéries pourraient puiser des éléments nutritifs à travers les pores de la surface cellulaire des Ciliés du rumen.

Vogels et al. (1980) observent une association des bactéries méthanogènes avec des Ciliés du rumen. Cette interaction somatique, selon ces auteurs, pourrait refléter une interaction métabolique dans laquelle le transfert d'hydrogène est bénéfique pour les deux espèces et stimule le processus de cellulolyse par fixation de $\mathrm{H}_{2}$.

De même, l'attachement des bactéries aux Ciliés du caecum pourrait ne pas être uniquement une association somatique; il s'y ajouterait une association physiologique permettant les échanges et favorisant la croissance de chacun des partenaires. Dans cette ectosymbiose, la nature des échanges entre Ciliés et bactéries du caecum reste à déterminer.

Reçu en juin 1984.

Accepté en octobre 1984

Remerciements. - Je remercie Madame Buthors pour son assistance technique, U.E.R Odontologie - Reims. 


\section{Références}

AKIN D. E., 1976. Ultrastructure of rumen bacteria attachment of forage cell walls. Appl. environm. Microbiol., 31, 562-568.

AMOS H. E., AKIN D. E., 1978. Rumen protozoal degradation of structurally intact forage tissues. Appl. environm. Microbiol., 36, 513-522.

ANDERSON T. F., 1951. The use of critical point phenomena in preparing specimens for the electron microscope. J. appl. Phys., 21, 724.

BAUCHOP T., 1979. The rumen ciliate Epidinium in primary degradation of plant tissues. Appl. environm. Microbiol., 37, 1217-1223.

BAUCHOP T., CLARKE R. T. 1976. Attachment of the ciliate Epidinium crawley to plant fragments in the sheep rumen. Appl. environm. Microbiol., 32, 417-422.

BONHOMME-FLORENTIN A., 1969. Essais de culture in vitro des Cycloposthiidae, Ciliés commensaux de l'intestin du Cheval. Rôle de ces Ciliés dans la dégradation de la cellulose. Protistologica, 5, 519-522.

BONHOMME-FLORENTIN A., 1971. Etude des métabolismes azoté et glucidique des Ciliés du genre Cycloposthium du caecum des Equidés. Protistologica, 7, 411-419.

BONHOMME-FLORENTIN A., 1974. Contribution à l'étude de la physiologie des Ciliés Entodiniomorphes endocommensaux des Ruminants et des Equidés. Ann. Sci. nat., 126, 155-283.

BONHOMME-FLORENTIN A., 1983. Biohydrogénation des acides gras insaturés de chloroplastes par les Protozoaires et les Bactéries du contenu du caecum de Cheval. Arch. Protistenk., 127, 399-404.

COLEMAN G. S., DAWSON R. M., GRIME D. W., 1980. The rate of passage of ciliate protozoa from the ovine rumen. Proc. Nutr. Soc., 39, 6A.

CURGY J. J., 1968. Influence du mode de fixation sur la possibilité d'observer des structures myéliniques dans les hépatocytes d'embryon de Poulet. J. Microsc., 7, 63-80.

GUILLAUMIN D., 1980. La pratique du microscope électronique à balayage en biologie. Masson, Paris.

HALL F. J., WEST J., COLEMAN G. S., 1974. Fine structural studies on the digestion of chloroplasts in the rumen ciliate Entodinium caudatum. Tissue Cell, 6-2, 243-253.

HUNGATE R. E., 1942. The culture of Eudiplodinium neglectum with experiments on the digestion of cellulose. Biol. Bull., 83, 303-319.

IMAI S., OGIMOTO K., 1978. Scanning electron and fluorescent microscopic studies on the attachment of spherical bacteria to ciliate protozoa in the ovine rumen. Jap. J. vet. Sci., 40, 1-19.

IMAI S., TSUNODA K., 1972. Scanning electron microscopic observations on the surface structures of ciliate protozoa in sheep rumen. Nat. Inst. anim. Health Quart., 12, 74-88.

JOUANY J. P., SENAUD J. 1978. Nutriments fournis à I'hôte par la flore et par la faune infusorienne du rumen. J. Protozool, Abstr. 173.

LICHTENHALER H. K., SPREY B., 1966. Über die osmiophilen globulären Lipideinschlüsse der Chloroplasten. Z. Naturf. B., 21, 690-697.

ORPIN C. G., 1979. Association of rumen ciliate protozoa with plant particles in vitro. Soc. gen. Microbiol. Quart., 7, G8.

ORPIN C. G., 1979. Chemotaxis in rumen ciliate protozoa. Soc. gen. Microbiol. Quart., 7, G9.

PALADE G. E., 1952. A study of fixation for electron microscopy. J. exp. Med., 95, 285-298.

REYNOLDS E. S., 1963. The use of lead citrate at high $\mathrm{pH}$ as an electron opaque strain in electron microscopy. J. Cell Biol., 17, 208-211.

SENAUD J., GRAIN J., 1984. Mécanismes d'ingestion et de digestion intracellulaire de particules végétales variées (luzerne fraîche). Etude comparée de deux Ciliés du rumen du Mouton Polyplastron multivesiculatum et Epidinium ecaudatum. J. Protozool. (sous presse).

VOGELS G. D., HOPPE W. F., STUMM C. K., 1980. Association of methanogenic bacteria with rumen ciliates. Appl. environm. Microbiol., 40, 608-612.

WEST J., MANGAN J. L., 1970. Effects of glutaraldehyde on the protein loss and photochemical properties of kale chloroplasts : preliminary studies on food conversion. Nature, 228, 466-468.

WEST J., MANGAN J. L., 1972. The digestion of chloroplasts in the rumen of sheep and the effect of disruption and glutaraldehyde treatment. Proc. Nutr. Soc., 31, 108A. 